\title{
Effects of Hypernatremia on Organic Brain Osmoles
}

Yeong-Hau H. Lien, Joseph I. Shapiro, and Laurence Chan

Department of Medicine, University of Colorado Health Sciences Center, Denver, Colorado 80262

\begin{abstract}
We studied the effects of varying degrees and durations of hypernatremia on the brain concentrations of organic compounds believed to be important, so-called "idiogenic" osmoles in rats by means of conventional biochemical assays, nuclear magnetic resonance spectroscopy, and high-performance liquid chromatography. There were no changes in the concentrations of these osmoles (specifically myoinositol, sorbitol, betaine, glycerophosphorylcholine [GPC], phosphocreatine, glutamine, glutamate, and taurine) in rats with acute ( 2 h) hypernatremia (serum Na 194 \pm 5 meq/liter). With severe (serum Na 180 \pm 4 meq/liter) chronic ( 7 d) hypernatremia, the concentrations of each of these osmoles except sorbitol increased significantly: myoinositol (65\%), betaine (54\%), GPC (132\%), phosphocreatine $(73 \%)$, glutamine $(143 \%)$, glutamate $(84 \%)$, taurine $(78 \%)$, and urea $(191 \%)$. Together, these changes account for $35 \%$ of the change in total brain osmolality. With moderate (serum Na 159 \pm 3 meq/liter) hypernatremia, more modest but significant increases in the concentrations of each of these osmoles except betaine and sorbitol were noted. When rats with severe chronic hypernatremia were allowed to drink water freely, their serum sodium as well as the brain concentrations of all of these organic osmoles except myoinositol returned to normal within $2 \mathrm{~d}$. It is concluded that: idiogenic osmoles play an important role in osmoregulation in the brain of rats subjected to hypernatremia; the development of these substances occur more slowly than changes in serum sodium; and the decrease in concentration of myoinositol occurs significantly more slowly than the decrease in serum sodium which occurs when animals are allowed free access to water. These observations may be relevant to the clinical management of patients with hypernatremia. (J. Clin. Invest. 1990. 85:1427-1435.) brain • high performance liquid chromatography • hypernatremia $\bullet$ idiogenic osmoles $\bullet$ nuclear magnetic resonance
\end{abstract}

\section{Introduction}

So-called "idiogenic" osmoles have been postulated to develop in the brain cells of patients suffering from chronic elevations in the osmolality of their extracellular fluid. Moreover, the rapid correction of the osmolality of such patients, especially

A portion of this work was presented to the annual meeting of the American Society of Nephrology, 1988 and published in abstract form (1989. Kidney Int. 35:498).

Address reprint requests to Dr. Chan, Department of Medicine, University of Colorado Health Sciences Center, 4200 East Ninth Avenue, Box C-281, Denver, CO 80262.

Received for publication 10 August 1989 and in revised form 19 December 1989.

J. Clin. Invest.

(C) The American Society for Clinical Investigation, Inc.

0021-9738/90/05/1427/09 \$2.00

Volume 85, May 1990, 1427-1435 pediatric patients, is associated with the development of cerebral edema (1). It has been known for more than 30 years that changes in tissue sodium and potassium concentrations cannot account for all of the observed change in tissue osmolality which occur during chronic hypernatremia (2). The inorganic and organic solutes that maintain equality between extracellular and intracellular brain osmolality during this adaptation to hyperosmotic stress have been investigated by several groups. Arieff and his associates $(3,4)$ demonstrated that organic osmoles accumulated in the brains of chronic but not acute hypernatremic rabbits. Other investigators have shown that the levels of some amino acids and their derivatives such as glutamine, glutamate, taurine, and urea rise in the brains of chronic hypernatremic animals, and account for about half of the increment of total brain osmoles $(5,6)$. However, many of the idiogenic osmoles have not yet been characterized in brain tissue.

Polyols and trimethylamines accumulate intracellularly in marine animals, plants, and bacteria when extracellular or environmental osmolarity is significantly increased $(7,8)$. Recently, with the use of nuclear magnetic resonance (NMR) ${ }^{1}$ spectroscopy, gas chromatography, and enzymatic analysis, polyols (sorbitol and myoinositol) and trimethylamines (glycerophosphorylcholine [GPC] and betaine) were identified in high concentrations in renal papillae of antidiuretic animals (9-12). It has not been tested whether these molecules also serve as osmoles in brain during adaptation to hyperosmolar states.

In this study, we investigated the significance of polyols and trimethylamines as idiogenic osmoles developing in the brain of hypernatremic rats using conventional biochemical assays, NMR spectroscopy, and high-performance liquid chromatography (HPLC). In addition, we examined the time course of the changes of these osmoles during the recovery phase of hypernatremia.

\section{Methods}

Animal models. Four groups of male Sprague-Dawley rats weighing $300-350$ g were investigated: group 1, normal rats; group 2, rats subjected to severe acute hypernatremia; group 3 , rats subjected to moderate chronic hypernatremia; and group 4 , rats subjected to severe chronic hypernatremia. Normal rats were allowed ad libitum normal rat chow (Wayne Lab Blox, Ralston Purina Co., St. Louis, MO) and water. Acute hypernatremia was induced by the intraperitoneal injection of $0.8 \mathrm{ml} / 100 \mathrm{~g}$ body weight of $4 \mathrm{M} \mathrm{NaCl}$ as described by Chan and Fishman (13). These rats were then killed $2 \mathrm{~h}$ after injection. Rats with moderate hypernatremia were gavaged with $1 \mathrm{ml} / 100 \mathrm{~g}$ body weight of $5 \% \mathrm{NaCl}$ twice daily for $7 \mathrm{~d}$ as described by Holliday et al. (14). Rats were allowed to eat solid food and drink 5\% saline ad libitum. Rats with severe chronic hypernatremia were treated similarly to

1. Abbreviations used in this paper: GABA, $\gamma$-aminobutyric acid; GPC, glycerophosphorylcholine; NMR, nuclear magnetic resonance; TSP, trimethylsilylproprionate. 
those in group 3 except that gavage with 5\% saline was administered every other day instead of daily.

In addition, the recovery phase of hypernatremia was studied. Rats with severe chronic hypernatremia were allowed to drink water ad lib. for 1 or $2 \mathrm{~d}$ and were then killed. Daily weights and serial serum osmolalities and $\mathrm{Na}$ and urea nitrogen concentrations during induction and therapy of hypernatremia were determined.

Preparation of brain extracts. Rats were anesthetized with pentobarbital $(50 \mathrm{mg} / \mathrm{kg}$ i.p.) and rapidly decapitated using a rodent guillotine with the head quick frozen in liquid nitrogen and stored until subsequent extraction at $-70^{\circ} \mathrm{C}$. Upon performance of the extraction procedure, a portion of brain tissue was dried at $100^{\circ} \mathrm{C}$ in an oven for $16 \mathrm{~h}$ to determine brain water content. The bulk of brain tissue was homogenized while cooled in liquid nitrogen and rapidly mixed with 4 $\mathrm{ml}$ of $6 \%$ perchloric acid. The mixture was then centrifuged at $0^{\circ} \mathrm{C}$ at $12,000 \mathrm{~g}$ for $20 \mathrm{~min}$. The supernatant was removed and neutralized to pH 7.0 with $30 \% \mathrm{KOH}$. The neutralized extract was then passed through a Sep-Pak C18 cartridge (Millipore Corp., Bedford, MA) and stored at $-70^{\circ} \mathrm{C}$.

Biochemical assays. Sorbitol content was measured by enzymatic assay with sorbitol dehydrogenase (EC 1.1.1.14) using commercial kits (No. 670057, Boehringer Mannheim Biochemicals, Indianapolis, IN). An aliquot of $200 \mu \mathrm{l}$ of brain extract was used for this assay.

Myoinositol content was measured by enzymatic assay with inositol dehydrogenase (EC 1.1.1.18, from Enterobacter aerogenes, Sigma Chemical Co., St. Louis, MO) as described by Weissbach (15). An aliquot of $25 \mu \mathrm{l}$ of brain extract was used for this assay.

Betaine content was measured by periodide precipitation method described by Barak and Tuma (16). An aliquot of $500 \mu \mathrm{l}$ of brain extract was used for this assay.

GPC content was measured by enzymatic assay with phospholipase D (EC 3.1.4.4, from Streptomyces chromofuscus, Boehringer Mannheim Biochemicals) and choline oxidase (EC 1.11.13.17, Sigma Chemical Co.) as described by Takayama et al. (17) and modified by Bagnasco et al. (11). An aliquot of $50 \mu \mathrm{l}$ of brain extract was used for this assay.

NMR spectroscopy. Brain osmoles were quantitated with NMR spectroscopy methods. An aliquot of $1 \mathrm{ml}$ of brain extract was lyophilized and reconstituted in $0.7 \mathrm{ml}$ of $\mathrm{D}_{2} \mathrm{O}$ containing $2.5 \mathrm{mM}$ sodium 3-trimethylsilylproprionate (TSP, Sigma Chemical Co.), an internal chemical shift and concentration standard, and placed in a $5-\mathrm{mm}$ NMR tube (Wilmad Glass Co., Inc., Buena, NJ). 'H-NMR spectroscopy was performed using a $300-\mathrm{MHz}(7.0 \mathrm{~T}) 10-\mathrm{cm}$ vertical-bore cryomagnet and an AM 300 spectrometer (Bruker Instruments, Inc., Billerica, MA). ${ }^{1} \mathrm{H}-\mathrm{NMR}$ spectra were obtained at $300 \mathrm{MHz}$ using a sweep width of $10 \mathrm{ppm}$ and $16 \mathrm{~K}$ data arrays, and 128 scans collected with $90^{\circ}$ pulses applied every $10 \mathrm{~s}$. The integral of each peak was analyzed relative to the integral of the TSP peak as described by Gullans and co-workers (12).

HPLC. HPLC was performed using a Sugar-Pak 1 column (Waters Associates, Milford, MA) as described by Wolff et al. (18). An aliquot of $50 \mu \mathrm{l}$ of brain extract was injected and eluted with $0.1 \mathrm{mM}$ calcium disodium EDTA at $0.5 \mathrm{ml} / \mathrm{min}$ and $80^{\circ} \mathrm{C}$. Metabolites were detected with a refractive index detector (Altex Scientific, Inc., Berkeley, CA) and analyzed with a computer (CDS 401, Varian Associates, Inc., Palo Alto, CA).

Statistics. One-way analysis of variance was performed to demonstrate differences among group means. Comparison of group means with the control was done using Student's $t$ test for unpaired data employing Scheffe's method to correct for multiple comparisons (19). Significance levels are reported at the $P<0.05$ and $P<0.01$ levels.

\section{Results}

Effects of hypernatremia on the concentrations of organic brain osmoles

Physiologic measurements. The serum sodium increased from $141 \pm 2$ to $194 \pm 5 \mathrm{meq} / \mathrm{liter} 2 \mathrm{~h}$ after hypertonic saline injection
Table I. Serum Sodium, Urea Nitrogen, Osmolality, and Brain Water Content

\begin{tabular}{lcccc}
\hline & \multicolumn{4}{c}{ Rat group $(n)$} \\
\cline { 2 - 5 } & $\begin{array}{c}\text { Normal } \\
(8)\end{array}$ & $\begin{array}{c}\text { Acute } \\
\text { hypernatremia } \\
(5)\end{array}$ & $\begin{array}{c}\text { Chronic } \\
\text { hypernatremia, } \\
\text { moderate } \\
(5)\end{array}$ & $\begin{array}{c}\text { Chronic } \\
\text { hypernatremia, } \\
\text { severe } \\
(6)\end{array}$ \\
\hline $\begin{array}{c}\text { Serum Na } \\
(m e q / l i t e r)\end{array}$ & $141 \pm 2$ & $194 \pm 5^{*}$ & $159 \pm 3^{*}$ & $180 \pm 4^{* *}$ \\
$\begin{array}{c}\text { Serum urea } \\
\text { nitrogen } \\
(m g / d l)\end{array}$ & $15 \pm 2$ & $28 \pm 3^{*}$ & $20 \pm 2$ & $43 \pm 5^{* \neq}$ \\
$\begin{array}{c}\text { Serum osmolality } \\
(m o s m o l / k g)\end{array}$ & $301 \pm 2$ & $402 \pm 8^{*}$ & $350 \pm 7^{*}$ & $403 \pm 9^{* *}$ \\
$\begin{array}{c}\text { Brain water } \\
\text { content }(\%)\end{array}$ & $77.6 \pm 1.0$ & $74.5 \pm 0.3^{*}$ & $77.4 \pm 0.6$ & $77.1 \pm 0.8$ \\
\hline
\end{tabular}

$n$, number of rats in each group. Values are means \pm SD.

${ }^{*} P<0.01$ vs. normal rats; ${ }^{\ddagger} P<0.01$ vs. moderate chronic hypernatremic rats.

(group 2). The serum osmolality increased from $301 \pm 2$ to $402 \pm 8 \mathrm{mosmol} / \mathrm{kg}$, and brain water content decreased from $77.6 \pm 1.0 \%$ to $74.5 \pm 0.3 \%$. Increases in serum urea nitrogen also occurred, probably reflecting prerenal azotemia (Table I).

Chronic hypernatremia developed with oral salt loading. When rats were gavaged with $5 \%$ saline daily, they developed moderate chronic hypernatremia with serum sodium $159 \pm 3$ $\mathrm{meq} / \mathrm{liter}$ and serum osmolality $350 \pm 7 \mathrm{mosmol} / \mathrm{kg}$ (group 4). When saline was given every other day, the rats developed severe chronic hypernatremia with serum sodium $180 \pm 4$ $\mathrm{meq} / \mathrm{liter}$ and osmolality $403 \pm 9 \mathrm{mosmol} / \mathrm{kg}$ (group 3 ) (Table I). It was noted that the serum urea nitrogen level was higher in rats with severe chronic hypernatremia than those with moderate chronic hypernatremia $(43 \pm 5$ vs. $20 \pm 2 \mathrm{mg} / \mathrm{dl})$. The rats with severe hypernatremia lost more weight than the rats with moderate hypernatremia ( $25 \%$ vs. $22 \%$ ). The brain water content in both groups was not significantly different from that in normal rats (Table I). In both groups, all the rats survived the induction of chronic hypernatremia.

Biochemical assays. Table II shows the concentrations of myoinositol, betaine, and GPC in brain tissue from each group of rats using biochemical assays. In normal rats, myoinositol, betaine, and GPC concentrations were $4.73 \pm 1.37,0.97 \pm 0.18$, and $0.83 \pm 0.12 \mathrm{mmol} / \mathrm{kg} \mathrm{H}_{2} \mathrm{O}$, respectively. The concentra-

Table II. Brain Osmoles Measured by Biochemical Assays

\begin{tabular}{|c|c|c|c|c|}
\hline & \multicolumn{4}{|c|}{ Rat group ( $n$ ) } \\
\hline & $\begin{array}{c}\text { Normal } \\
(8)\end{array}$ & $\begin{array}{c}\text { Acute } \\
\text { hypernatremia } \\
\text { (5) }\end{array}$ & $\begin{array}{c}\text { Chronic } \\
\text { hypernatremia, } \\
\text { moderate } \\
(5)\end{array}$ & $\begin{array}{c}\text { Chronic } \\
\text { hypernatremia, } \\
\text { severe } \\
\text { (6) }\end{array}$ \\
\hline & \multicolumn{4}{|c|}{$\mathrm{mmol} / \mathrm{kg} \mathrm{H}_{2} \mathrm{O}$} \\
\hline Myoinositol & $4.73 \pm 1.37$ & $5.76 \pm 2.06$ & $7.50 \pm 1.06^{\ddagger}$ & $8.55 \pm 1.07^{*}$ \\
\hline Betaine & $0.97 \pm 0.18$ & $0.90 \pm 0.08$ & $1.14 \pm 0.16$ & $1.92 \pm 0.45^{*}$ \\
\hline GPC & $0.83 \pm 0.12$ & $0.78 \pm 0.11$ & $1.19 \pm 0.16^{\ddagger}$ & $2.19 \pm 0.32^{*}$ \\
\hline
\end{tabular}

$n$, number of rats in each group. Values are means \pm SD.

${ }^{*} P<0.01$ vs. normal rats; ${ }^{\ddagger} P<0.05$ vs. normal rats. 
tions of these three osmoles were unchanged in rats with acute hypernatremia. In rats with severe chronic hypernatremia, the concentrations of myoinositol, betaine, and GPC were increased significantly to $8.55 \pm 1.07,1.92 \pm 0.45$, and $2.19 \pm 0.32$ $\mathrm{mmol} / \mathrm{kg} \mathrm{H}_{2} \mathrm{O}$, respectively. In rats with moderate chronic hypernatremia, both myoinositol and GPC increased signifcantly to $7.50 \pm 1.06$ and $1.19 \pm 0.16 \mathrm{mmol} / \mathrm{kg} \mathrm{H}_{2} \mathrm{O}$, whereas the concentration of betaine was not different. from that of normal rats. The sorbitol concentration was very low in brain tissue of normal rats $\left(75 \pm 13 \mu \mathrm{mol} / \mathrm{kg} \mathrm{H}_{2} \mathrm{O}\right)$ and rats with severe chronic hypernatremia $\left(83 \pm 17 \mu \mathrm{mol} / \mathrm{kg} \mathrm{H}_{2} \mathrm{O}\right)$ and was not significantly different between the two groups.

NMR spectroscopy. Fig. 1 shows the ${ }^{1} \mathrm{H}-\mathrm{NMR}$ spectra of brain extract from a normal rat $(A)$ and a rat with severe chronic hypernatremia $(B)$. The most prominent peaks represent $N$-acetyl aspartate $(2.02 \mathrm{ppm})$ and phosphocreatine (3.03

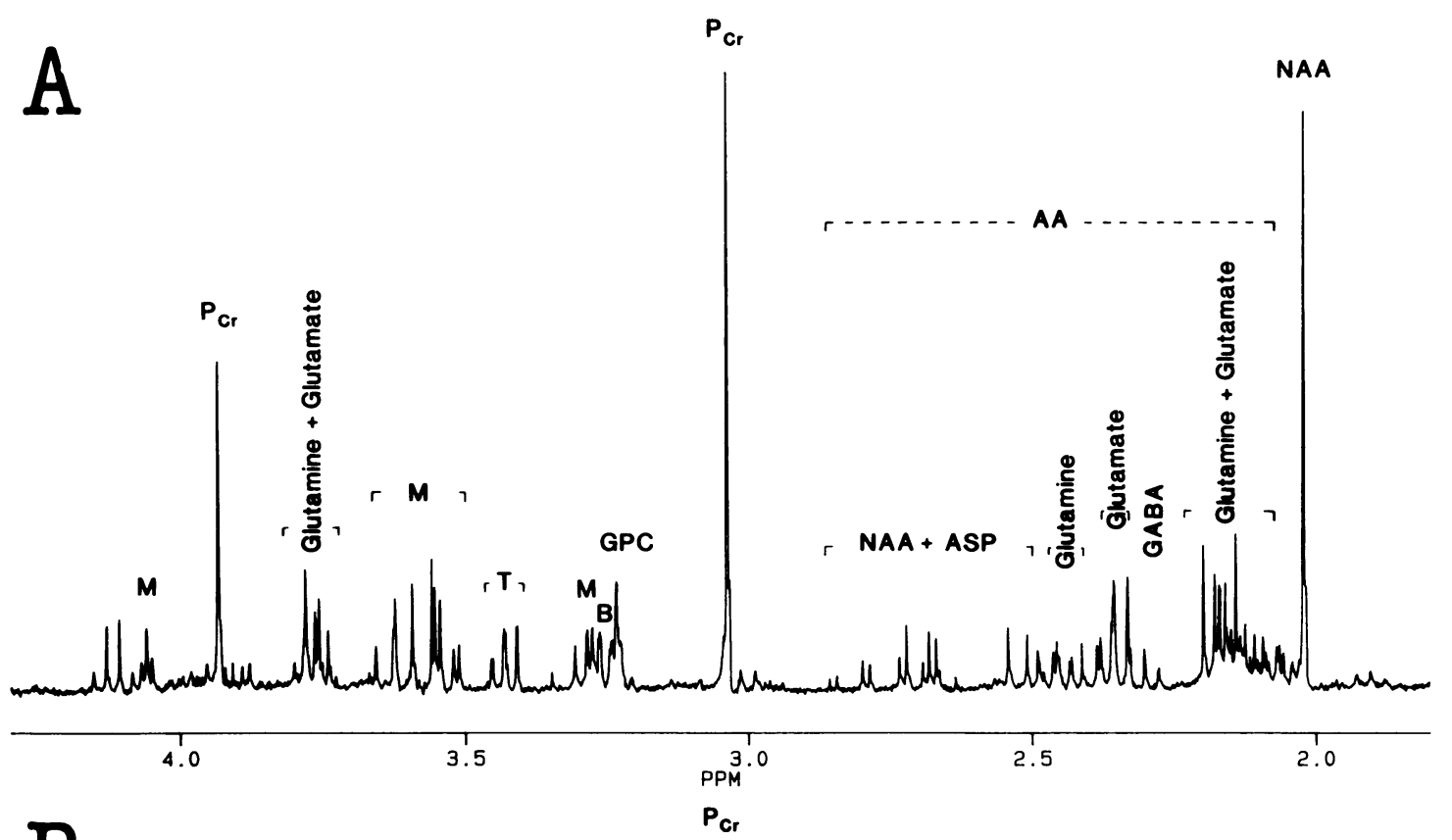

$\mathrm{B}$

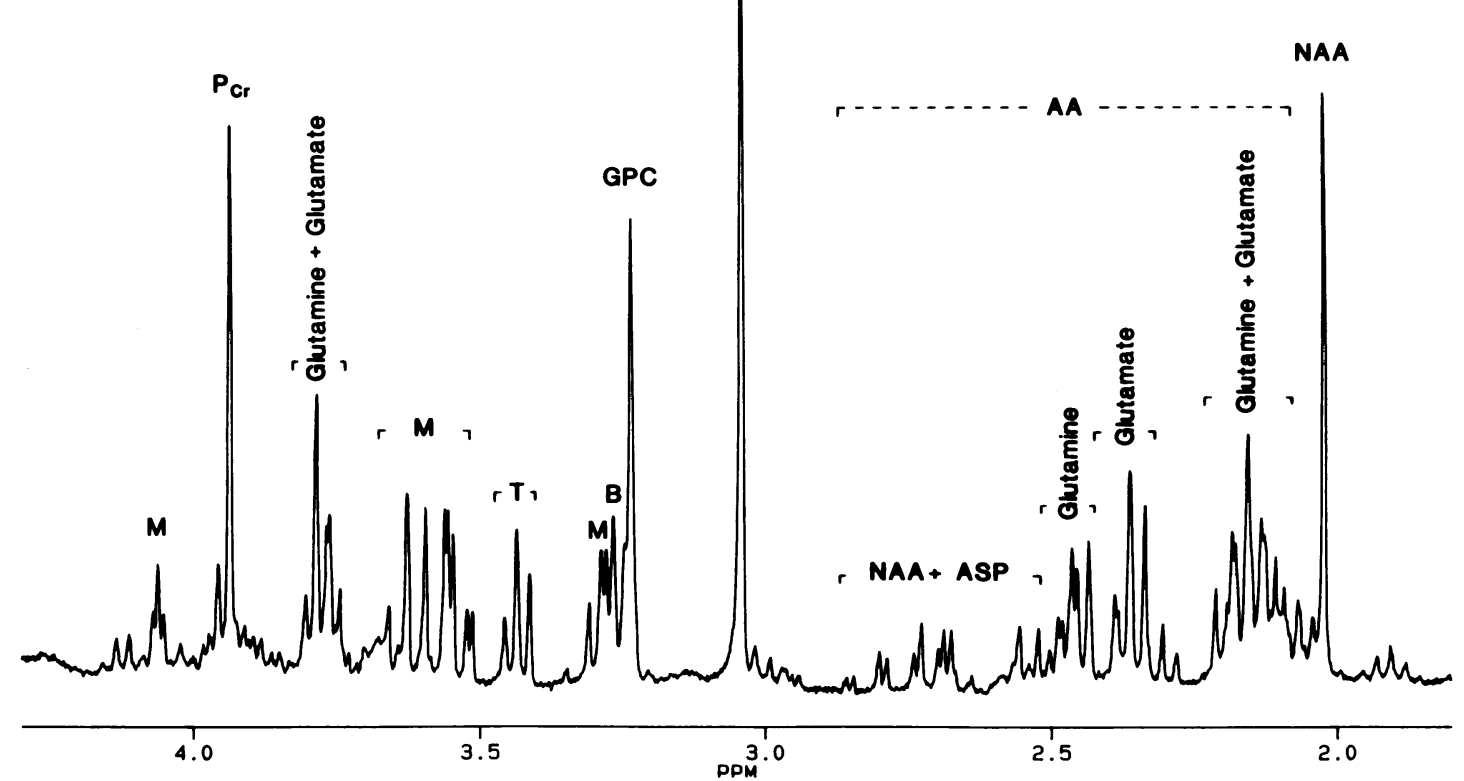

Figure 1. 'H-NMR spectra of brain extracts. $(A)$ Normal rat; $(B)$ severe chronic hypernatremic rat. These spectra are sum of 128 transients each and are referenced to TSP. Peaks derived from $N$-acetyl aspartate $(N A A), \gamma$-aminobutyric acid $(G A B A)$, glutamine, glutamate, aspartate $(A S P)$, amino acids $(A A)$, phosphocreatine $(P C r)$, glycerophosphorylcholine $(G P C)$, betaine $(B)$, taurine $(T)$, and myoinositol $(M)$ have been labeled. 
and $3.93 \mathrm{ppm}$ ). The peak area of $N$-acetyl aspartate (relative to TSP) in chronic severe hypernatremia was not different from normal, while the relative peak area of phosphocreatine was markedly increased with severe chronic hypernatremia. The peaks in the range $2.0-2.8 \mathrm{ppm}$ represent primarily amino acids including glutamate $(2.32,2.34,2.36 \mathrm{ppm})$, glutamine $(2.38,2.40,2.42 \mathrm{ppm})$, aspartate $(2.78,2.80,2.84,2.86 \mathrm{ppm})$. It was evident that the relative peak areas of glutamate and glutamine were greater in rats with severe chronic hypernatremia than normal rats. The major peaks of polyols and trimethylamines were located between 2.1 and 3.9 ppm: GPC, 3.23; betaine, 3.26; myoinositol, 3.27, 3.57, 3.59, 3.61, and 4.06; and sorbitol, $3.85 \mathrm{ppm}$. We observed the increases in the peak areas attributable to GPC, betaine, and myoinositol in rats with severe chronic hypernatremia compared with normal rats. The sorbitol peak was not visualized in either spectra, reflecting the low concentrations of this substance in rat brain. Also noted in this region were peaks attributable to taurine $(3.41,3.43,3.45 \mathrm{ppm})$ as well as glutamine and glutamate $(3.72-3.79 \mathrm{ppm})$. The peaks attributable to all three amino acids were increased in hypernatremic rats. The spectra of brain extracts from rats with acute hypernatremia were similar to those of normal rats and, thus, were not shown. Table III shows the results of osmole quantitation using the ${ }^{1} \mathrm{H}-\mathrm{NMR}$ studies of brain extracts from the four groups of rats. The concentrations of myoinositol, betaine, and GPC in the brain of normal rats were $4.61 \pm 0.77,0.14 \pm 0.05$, and $1.00 \pm 0.21$ $\mathrm{mmol} / \mathrm{kg} \mathrm{H}_{2} \mathrm{O}$, respectively. The changes in brain osmoles in each experimental condition were consistent with those from the biochemical assays (Table II), i.e., myoinositol, betaine, and GPC were increased significantly in rats with severe chronic hypernatremia $(7.63 \pm 1.56, P<0.01 ; 0.26 \pm 0.09, P$ $<0.05$; and $3.09 \pm 0.29, P<0.01$ ), but did not change in rats with acute hypernatremia. In rats with moderate chronic hypernatremia, myoinositol $(7.01 \pm 1.18, P<0.01)$ and GPC $(1.56 \pm 0.12, P<0.01)$ were increased, but betaine was unchanged. It was noted that the amount of myoinositol and GPC detected was comparable with these two methods, while betaine concentrations measured with periodide precipitation method were seven to eight times higher than when measured with the NMR method.
The results of quantitation of other organic molecules with prominent peaks are also shown in Table III. The phosphocreatine concentrations were increased significantly in chronic moderate $(4.11 \pm 0.54)$ and severe $(5.21 \pm 0.15)$ hypernatremic animals compared to control $(3.01 \pm 0.38)$ and acute hypernatremic rats $(2.79 \pm 0.43)$. Glutamate, glutamine, and taurine which are the most abundant amino acids and their derivatives in rat brain, all increased significantly in chronic moderate hypernatremia $(17.14 \pm 2.37,7.30 \pm 0.33$, and $3.68 \pm 0.38$ $\mathrm{mmol} / \mathrm{kg} \mathrm{H}_{2} \mathrm{O}$, respectively) and chronic severe hypernatremia $(21.76 \pm 1.41,10.16 \pm 0.88$, and $5.40 \pm 0.45)$ compared to those in controls $(11.84 \pm 0.95,4.30 \pm 0.34$, and $2.65 \pm 0.28)$. In acute hypernatremic rats, there were no significant changes in the concentrations of these three amino acids. The level of $\mathrm{N}$-acetyl aspartate was also quantitated and was not significantly different among the four groups. Other amino acids which are less abundant were not measured.

$H P L C$. Fig. 2 shows representative chromatograms of brain extracts from a normal rat $(a)$ and a rat with severe chronic hypernatremia $(b)$. The peak assignments were: $A$, glucose (retention time in minutes, 8.1); $B$, myoinositol (10.1); $C$, taurine (11.0); $D$, unidentified metabolite (11.5), $E$, GPC (12.4); $F$, unidentified metabolite (14.9); $G$, urea (15.6); $H$, glutamine (17.1); and $I$, betaine (18.0). The peak assignments were in agreement with those reported by Wolff et al. (18). It was noted that the peak areas of myoinositol, taurine, GPC, urea, glutamine, and betaine were all increased in rats with severe chronic hypernatremia. The retention time for sorbitol was $13.4 \mathrm{~min}$. There was no measurable peak corresponding to sorbitol observed on any chromatogram.

The results of quantitation of major organic osmoles from HPLC studies are summarized in Table IV. The concentrations of myoinositol, betaine, and GPC in brain tissue of nor$\mathrm{mal}$ rats were $6.01 \pm 0.23,0.48 \pm 0.09$, and $1.27 \pm 0.18 \mathrm{mmol} / \mathrm{kg}$ $\mathrm{H}_{2} \mathrm{O}$, respectively. The changes of myoinositol, betaine, and GPC in each experimental condition were consistent with those obtained from biochemical assay and NMR studies. In rats with acute hypernatremia, there were no significant changes in the concentrations of these three osmoles. In rats with severe chronic hypernatremia, myoinositol $(7.89 \pm 0.45, P$ $<0.01)$, betaine $(0.74 \pm 0.08, P<0.01)$, and GPC $(2.95 \pm 0.18$,

Table III. Brain Osmoles Measured by NMR Methods

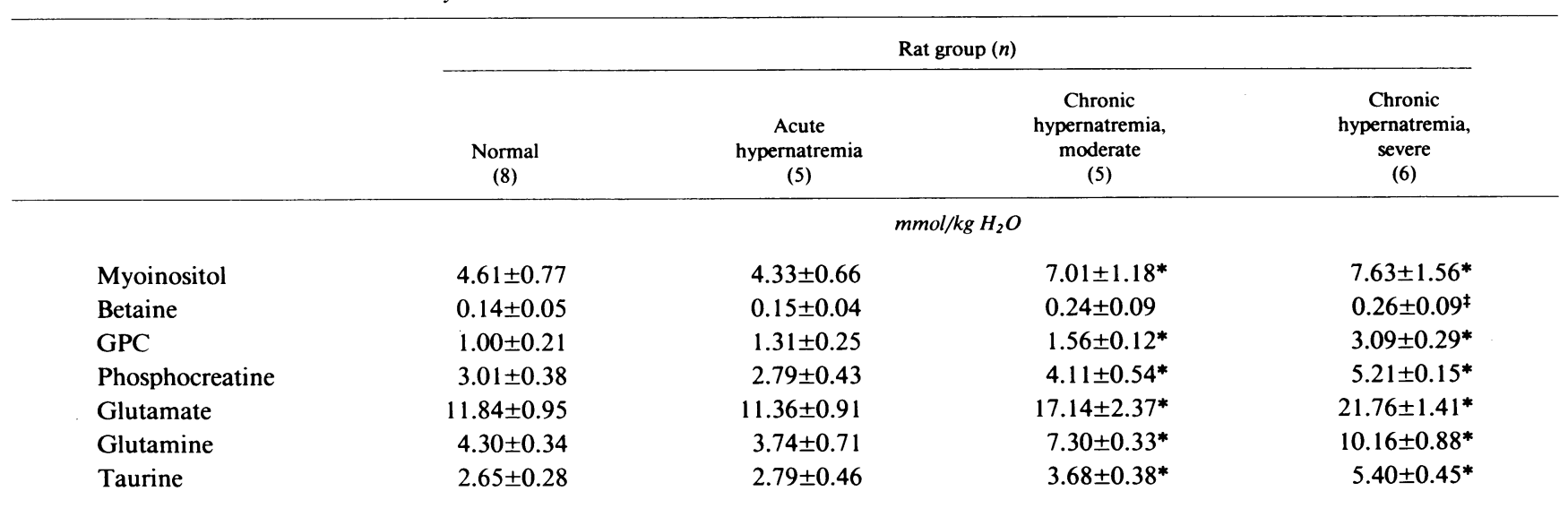

$n$, number of rats in each group. Values are means $\pm \mathrm{SD} . \quad{ }^{*} P<0.01$ vs. normal rats; ${ }^{\ddagger} P<0.05$ vs. normal rats. 

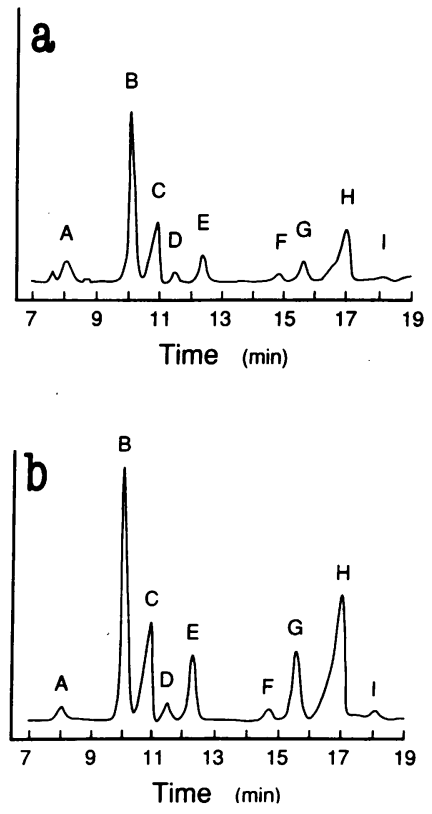

Figure 2. HPLC chromatograms of brain extracts. (a) Normal rat; $(b)$ severe chronic hypernatremic rat. For comparison, the same amount of brain extract from each rat was applied to the Sugar-Pak 1 column and eluted with $\mathrm{Ca}$ EDTA at $0.5 \mathrm{ml} / \mathrm{min}$ and $80^{\circ} \mathrm{C}$. Peak assignments are: $A$, glucose; $B$, myoinositol; $C$, taurine; $D$, unidentified; $E$, GPC; $F$, unidentified; $G$, urea; $H$, glutamine; and $I$, betaine.

$P<0.01)$ were increased significantly compared with normal rats. In rats with moderate chronic hypernatremia, myoinositol $(7.31 \pm 0.89, P<0.05)$ and GPC $(1.88 \pm 0.36, P<0.05)$ were significantly increased, whereas betaine $(0.53 \pm 0.07, P=\mathrm{NS})$ was not. The concentrations of myoinositol and GPC determined with the three methods were similar. The betaine concentrations measured with HPLC were between the values measured with the biochemical assay and NMR methods.

As for glutamine, taurine, and urea, the concentrations were $4.37 \pm 0.37,3.62 \pm 0.43$, and $4.40 \pm 0.66 \mathrm{mmol} / \mathrm{kg} \mathrm{H}_{2} \mathrm{O}$ in normal rats. In rats with acute hypernatremia, only urea increased significantly to $7.59 \pm 0.80(P<0.01)$. In rats with moderate chronic hypernatremia, concentrations of glutamine $(7.18 \pm 0.46)$ and taurine $(5.42 \pm 0.43)$ increased significantly compared with normal rats (both $P<0.01$ ). In rats with severe chronic hypernatremia, glutamine $(10.62 \pm 0.67)$, taurine $(6.45 \pm 0.44)$, and urea $(12.82 \pm 1.72)$ were all significantly elevated compared to normal rats (all $P<0.01$ ). The change of

Table IV. Brain Osmoles Measured by HPLC Methods

\begin{tabular}{|c|c|c|c|c|}
\hline & \multicolumn{4}{|c|}{ Rat group (n) } \\
\hline & $\begin{array}{c}\text { Normal } \\
\text { (4) }\end{array}$ & $\begin{array}{c}\text { Acute } \\
\text { hypernatremia } \\
\text { (4) }\end{array}$ & $\begin{array}{c}\text { Chronic } \\
\text { hypernatremia, } \\
\text { moderate } \\
\text { (4) }\end{array}$ & $\begin{array}{c}\text { Chronic } \\
\text { hypernatremia, } \\
\text { severe } \\
\text { (4) }\end{array}$ \\
\hline & \multicolumn{4}{|c|}{$\mathrm{mmol} / \mathrm{kg} \mathrm{H}_{2} \mathrm{O}$} \\
\hline Myoinositol & $6.01 \pm 0.23$ & $5.93 \pm 0.15$ & $7.31 \pm 0.89^{\ddagger}$ & $7.89 \pm 0.45^{*}$ \\
\hline Betaine & $0.48 \pm 0.09$ & $0.54 \pm 0.09$ & $0.53 \pm 0.07$ & $0.74 \pm 0.08^{*}$ \\
\hline GPC & $1.27 \pm 0.18$ & $1.47 \pm 0.22$ & $1.88 \pm 0.36^{\ddagger}$ & $2.95 \pm 0.18^{*}$ \\
\hline Glutamine & $4.37 \pm 0.37$ & $4.56 \pm 0.68$ & $7.18 \pm 0.46^{*}$ & $10.62 \pm 0.67^{*}$ \\
\hline Taurine & $3.62 \pm 0.43$ & $3.47 \pm 0.56$ & $5.42 \pm 0.43^{*}$ & $6.45 \pm 0.44^{*}$ \\
\hline Urea & $4.40 \pm 0.66$ & $7.59 \pm 0.80^{*}$ & $6.04 \pm 0.20$ & $12.82 \pm 1.72^{*}$ \\
\hline
\end{tabular}

$n$, number of rats in each group. Values are means \pm SD.

${ }^{*} P<0.01$ vs. normal rats; ${ }^{\ddagger} P<0.05$ vs. normal rats.

brain urea was in proportion to that of serum urea nitrogen (Table I).

\section{Organic osmole concentrations during recovery from hypernatremia}

Physiologic studies. Rats with severe hypernatremia were allowed to drink water ad lib. and killed 1 or $2 \mathrm{~d}$ later. Fig. 3 shows the time course of the changes in body weight $(A)$, serum sodium $(B)$, and brain water contents $(C)$ during the recovery phase. The rats gained $17 \pm 1 \%$ of initial body weight within 24 $h$ of free water access. On the second day they gained another $5 \%$. The serum sodium dropped from $180 \pm 4$ to $155 \pm 3$ in the
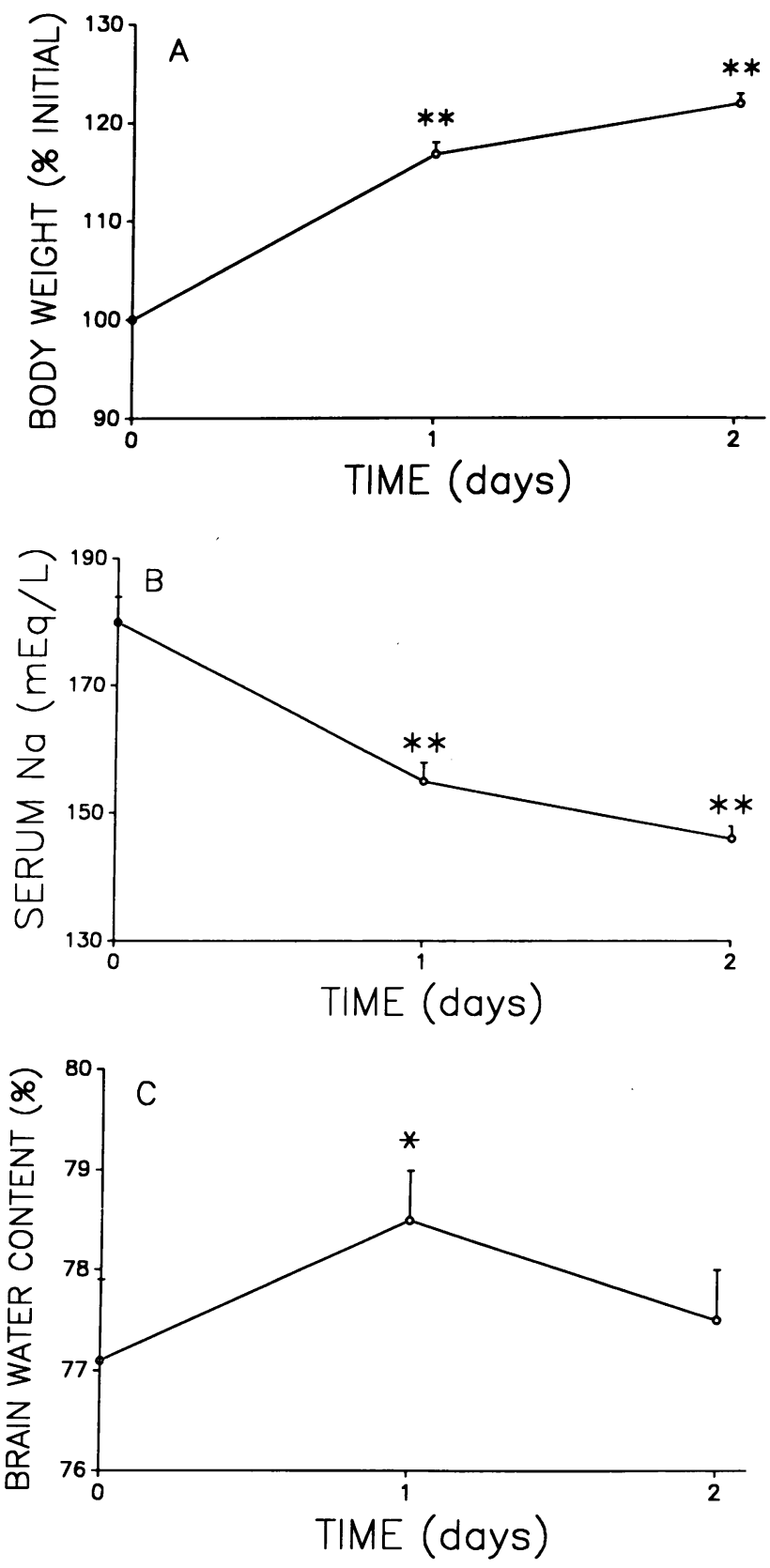

Figure 3. Physiologic studies of the recovery phase from severe chronic hypernatremia. Time course of the change of $(A)$ body weight, $(B)$ serum sodium, and $(C)$ brain water content. ${ }^{*} P<0.05$ and ${ }^{* *} P<0.01$ vs. initial value. 
first day and to $146 \pm 2 \mathrm{meq} / \mathrm{liter}$ in the second day. The brain water content increased slightly from $77.1 \pm 0.8 \%$ to $78.5 \pm 0.5 \%$ on the first day then returned to the normal range on the second day. All the rats survived the recovery from chronic hypernatremia prior to sacrifice.

NMR spectroscopy and HPLC measurements. Fig. 4 shows the time course of the changes in myoinositol $(A)$, betaine $(B)$, and GPC $(C)$ concentrations as measured with ${ }^{1} \mathrm{H}$-NMR spectroscopy in rat brains obtained during the recovery from chronic severe hypernatremia. It was noted that myoinositol
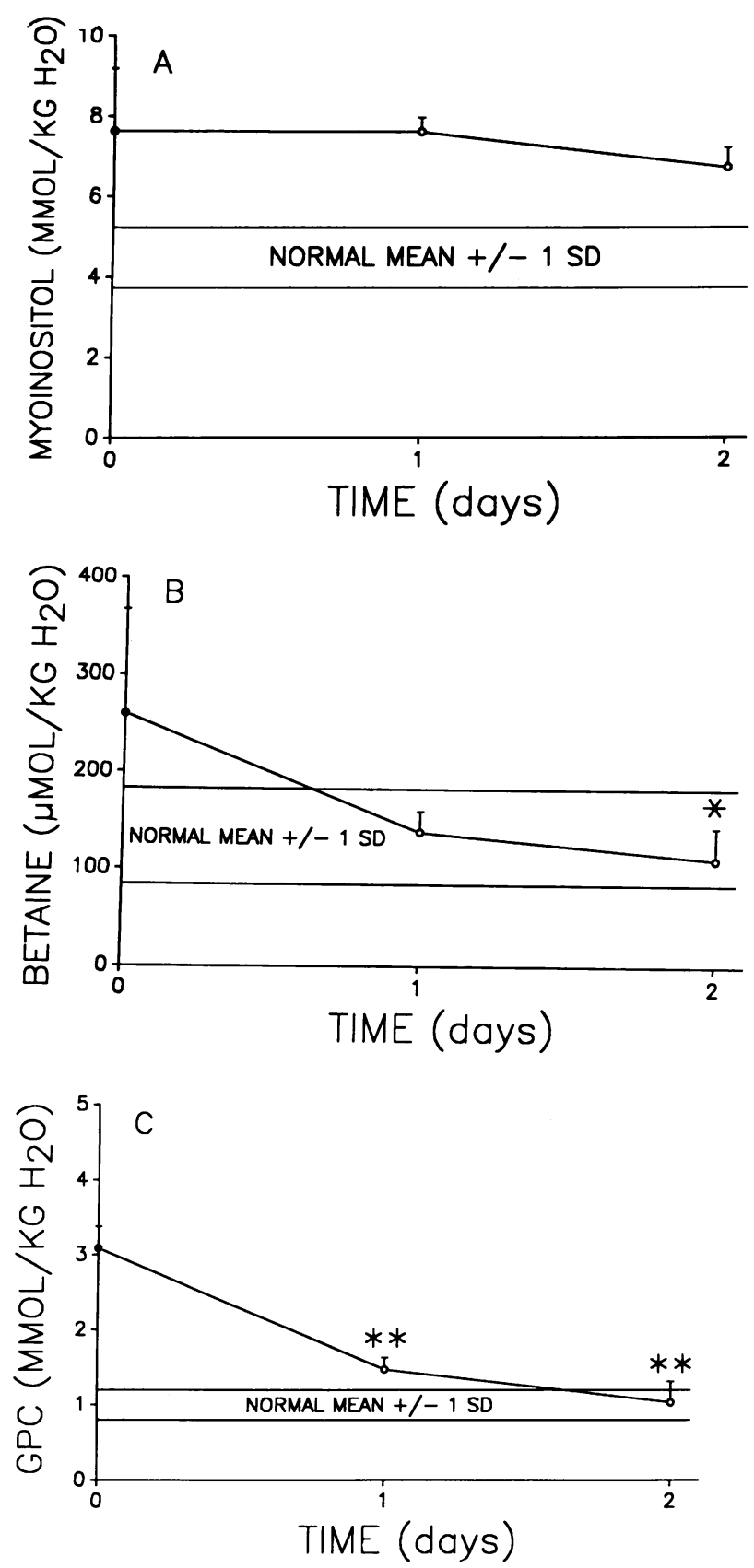

Figure 4. Time course of the change in organic brain osmole concentrations during recovery from severe chronic hypernatremia. $(A)$ Myoinositol; $(B)$ betaine; and $(C)$ GPC. ${ }^{*} P<0.05$ and ${ }^{* *} P<0.01$ vs. value seen in untreated severe chronic hypernatremia. The horizontal zone indicates the normal range of the individual osmoles (normal mean $\pm 1 \mathrm{SD}$ ). was not changed on the first day and only reduced slightly on the second day to a value still above the normal range (6.73 \pm 0.50 vs. $4.61 \pm 0.77 \mathrm{mmol} / \mathrm{kg} \mathrm{H}_{2} \mathrm{O}, P<0.05$ ). Betaine and GPC, however, reduced rapidly to $0.14 \pm 0.02$ and $1.47 \pm 0.16 \mathrm{mmol} / \mathrm{kg} \mathrm{H}_{2} \mathrm{O}$ on day 1 and returned to within the normal range $(0.11 \pm 0.03$, and $1.03 \pm 0.28$, respectively) on day 2. Phosphocreatine $(3.45 \pm 0.58)$, glutamine $(4.42 \pm 0.52$ $\left.\mathrm{mmol} / \mathrm{kg} \mathrm{H}_{2} \mathrm{O}\right)$, glutamate $(11.51 \pm 1.32)$, and taurine $\left(2.43 \pm 0.29 \mathrm{mmol} / \mathrm{kg} \mathrm{H} \mathrm{H}_{2} \mathrm{O}\right)$ concentrations measured with NMR also returned to within the normal range $2 \mathrm{~d}$ after access to free water. The results of quantitation of myoinositol, betaine, GPC, glutamine, and taurine with HPLC in this timecourse study were in close agreement with those obtained from ${ }^{1} \mathrm{H}-\mathrm{NMR}$.

\section{Discussion}

Organic molecules serve important biological functions in the process of cellular osmoregulation. When extracellular osmolality increases, organic molecules accumulate in the cells, thus, maintaining cell volume and counteracting the perturbation of enzyme function and protein structure by high concentrations of inorganic ions and other molecules such as urea $(7,8)$.

There appear to be three major groups of organic molecules which serve a function as biological osmoles: polyols, trimethylamines and amino acids and their derivatives $(7,8)$. In the past, the studies of brain in hyperosmolar state have been mainly focused on the accumulation of amino acids and their derivatives. Arieff and others reported a doubling of brain amino acid content in response to chronic hypernatremia in rabbits (3). In this study, the increase of amino acid accounted for approximately half of the estimated idiogenic osmoles, assuming the amino acids were present in an osmotically active form in brain cells. Thurston and coworkers have reported increases in 16 of 19 amino acids measured in the brains of hypernatremic mice (6). Although Ullrich reported high concentration of GPC in dog papilla as early as 1956 (20) the importance of polyols and trimethylamines in the osmoregulation in mammalian tissue has been only rediscovered recently by Balaban, Guder, Burg, Gullans, and their associates $(9-12,21)$. In this study, using three different approaches, we have demonstrated that the brain concentrations of myoinositol, betaine, and GPC, the major osmoles in renal papilla, are increased in the brain of rats with chronic hypernatremia, but not in acute hypernatremia (Tables II-IV). Whereas myoinositol and GPC concentrations increase in response to both moderate and severe hypernatremia, betaine concentrations, apparently, increase only when hypernatremic is severe. Sorbitol, another renal osmole, is present in very low concentrations in rat brain which does not change with hypernatremia. Phosphocreatine, a methylamine which does not play a role as osmole in renal papilla, however, is increased in response to chronic hypernatremia, but not to acute hypernatremia. Altogether, myoinositol, betaine, GPC, and phosphocreatine can account for about $7 \%$ of the total brain osmolality change during chronic severe hypernatremia.

Although in general, the three methods of chemical analysis agreed quite well, there was a discrepancy between the NMR and HPLC measurements of betaine with the biochemical method which consistently yielded higher values. This dis- 
crepancy is probably due to nonspecific precipitation of periodide with other trimethylamines which could effect the biochemical method but not the NMR or HPLC techniques.

There are very few reports on the brain content of polyols and trimethylamines in the literature. Wirthensohn and others have reported that the GPC content in rat brain is $0.70 \mathrm{mmol} /$ $\mathrm{kg}$ wet weight or $0.90 \mathrm{mmol} / \mathrm{kg} \mathrm{H}_{2} \mathrm{O}(21)$, which is in agreement with our results. Arieff et al. (22) have reported that myoinositol and sorbitol levels in rat brain were 6.3 and 0.05 $\mathrm{mmol} / \mathrm{kg} \mathrm{H}_{2} \mathrm{O}$, respectively. Both were similar to the values we obtained from rat brain extracts. More recently, while this manuscript was in preparation, Heilig et al. (23) presented their NMR measurements of brain osmole contents in rats subjected to a degree of chronic hypernatremia (serum sodium $151 \mathrm{meq} / \mathrm{liter}$ ) similar to that seen in our moderate chronic hypernatremia model. They reported that the normal brain myoinositol, betaine, and GPC levels were 62,3 , and $8 \mathrm{nmol} /$ mg protein, respectively, while in chronic hypernatremic rats, the levels were 90,3 , and $13 \mathrm{nmol} / \mathrm{mg}$ protein, respectively. These results are similar to those observed in our study. The levels of amino acids and phosphocreatine in rat brain measured in our study are consistent with previous studies $(5,6$, 23). Our observations confirmed that glutamine, glutamate and taurine are the major amino acids involved in brain osmoregulation. The response of phosphocreatine to chronic hypernatremia is also in agreement with the recent study by Heilig et al. (23).

The animal models we adopted are similar to those reported by Holliday et al. (14), and our physiologic findings concerning changes in serum sodium, and osmolality in general agree with theirs. Interestingly, the rats developed severe chronic hypernatremia in our studies received less salt than those with moderate hypernatremia. It is likely that rats with severe hypernatremia were in volume depletion state which was evident by the fact that the serum urea nitrogen level was higher in rats with severe hypernatremia than in rats with moderate hypernatremia and that there was more weight loss in rats with severe hypernatremia. The volume depletion stimulates the renin-angiotensin-aldosterone system thus reduces the urinary loss of sodium and facilitates development of hypernatremia (24). Our results concerning brain water and osmole content in rats with acute hypernatremia were also consistent with previous studies in this area (4): $2 \mathrm{~h}$ after high concentrated saline injection, the brain water content was reduced while brain osmoles remained in the normal range. As Arieff and co-workers $(3,4)$ suggested, in acute hypernatremia, there is no measurable difference between intracellular and extracellular fluid osmolality because of water efflux and increases in intracellular ion concentrations. In rats with moderate and severe chronic hypernatremia, the brain water content is within the normal range (Table I), and osmolality is not different between intracellular and extracellular fluids, primarily because of increases in the cellular concentrations of organic osmotically active molecules.

The contribution of the organic osmoles to the total osmolality change in chronic hypernatremia is substantial. To calculate the contribution, we have to assume that all of these molecules are osmotically active, thus the osmotic activity coefficient of individual molecule is close to 1 . The total increment of myoinositol, betaine, GPC, and phosphocreatine in the brain of rats with severe chronic hypernatremia is estimated to be $7 \mathrm{mmol} / \mathrm{kg} \mathrm{H}_{2} \mathrm{O}$. As the osmolality increases by about $100 \mathrm{mosmol} / \mathrm{kg}$, the contribution of these four osmoles is about $7 \%$. The increases of glutamate, glutamine and taurine (Tables III and IV) are consistent with previous reports $(5,6)$ and account for about $20 \%$ of estimated increase in osmolality. The concentration of urea in brain tissue is similar to the serum urea concentration as urea is freely permeable to the cell membrane (3). The contribution of urea to the total osmolality change is about $8 \%$. Altogether, the organic osmoles measured in this study can account about $35 \%$ of the total osmolality change in chronic hypernatremia.

Idiogenic osmoles have been postulated to be the molecules which fill up the gap between the measured change of osmolality and total changes contributed by electrolytes $(2,3)$. As mentioned above, the organic molecules which we measured can account for $35 \%$ of the total osmolality change in the brain during chronic hypernatremia. We, therefore, reviewed previous studies in this area in order to estimate the percentage of the osmolality which is still "idiogenic." The contributions of electrolytes and other solutes to the changes in brain osmolality for various durations and degrees of hypernatremia reported in different studies are summarized in Table V. In acute hypernatremia, it appears that changes in the concentration of brain electrolytes account for the majority of osmolality change as Arieff et al. (3) have been suggested. In chronic hypernatremia, the contribution of electrolyte concentration changes to the change in brain osmolality appears to be controversial. In the study by Holliday and his co-workers (14), the contribution of potassium is only $1 \%$. However, when intracellular potassium was calculated, the increment was 10 $\mathrm{mmol} / \mathrm{kg}$ consisting of $12 \%$ of the change of intracellular osmolality. The contributions of both sodium and chloride are in the range of $23-50 \%(3,6,14)$ arising mainly from the increase in concentration of these electrolytes in the extracellular fluid. The increase of intracellular sodium can only account for $4 \%$ of the change of intracellular osmolality (14). The total contribution of electrolytes to the changes in tissue osmolality can be estimated about $50-60 \%$. The wide range of contributions of amino acids to the total change in tissue osmolality are primarily due to differences in the selection of amino acids measured. It was highest (42\%) when total amino acids were quantitated with the Ninhydrin test (3) and lowest (8\%) when only glutamine, glutamate, and aspartate were measured (5). In general, the contributions of organic solutes to the observed change in brain osmolality during hypernatremia are: amino acids $20-30 \%$, urea $8-9 \%$, and polyols and methylamines, together $7-10 \%$. Therefore, the vast majority of total change in brain osmolality can be accounted by changes in the concentrations of measured solutes. In other words, there are no significant idiogenic brain osmoles.

During the recovery phase of hypernatremia, serum sodium and body weight returns to nearly normal in $2 \mathrm{~d}$. The brain water content increased $24 \mathrm{~h}$ after free access to water and then returned to a normal level on the second day. The rats appeared to tolerate this treatment well. The concentrations of betaine and GPC (Fig. 4, $B$ and $C$ ) as well as phosphocreatine, glutamine, glutamate, and taurine in brain tissue declined in parallel to the reduction in serum sodium concentration. However, myoinositol concentrations remained elevated even when serum $\mathrm{Na}$ returned to normal (Fig. $4 A$ ). It is not clear why the organic osmoles behave differently during the recovery phase, and this is certainly a topic for further investigation. 
Table V. Contribution of Electrolytes and Other Solutes to the Osmolality Change in Brains of Animals with Hypernatremia

\begin{tabular}{|c|c|c|c|c|c|c|c|}
\hline \multirow[b]{2}{*}{ Duration } & \multirow{2}{*}{$\begin{array}{l}\text { Animal } \\
\text { species }\end{array}$} & \multirow{2}{*}{$\begin{array}{l}\text { Change of } \\
\text { osmolality }\end{array}$} & \multicolumn{4}{|c|}{ Contribution to osmolality change } & \multirow{2}{*}{$\begin{array}{l}\text { Reference } \\
\text { number }\end{array}$} \\
\hline & & & $\mathrm{Na}^{+}$ & $\mathrm{K}^{+}$ & $\mathrm{Cl}^{-}$ & Other solutes & \\
\hline & & $\mathrm{mmol} / \mathrm{kg}$ & & & $\%$ & & \\
\hline \multirow{2}{*}{\multicolumn{8}{|c|}{$\begin{array}{l}\text { Acute hypernatremia } \\
h\end{array}$}} \\
\hline & & & & & & & \\
\hline 1 & Rat & 139 & 24 & 24 & ND & $\begin{array}{l}\text { Amino acids, } 1 \\
\text { Urea, } 4\end{array}$ & 13 \\
\hline 1 & Rabbit & 60 & 38 & 32 & 18 & ND & 3 \\
\hline 2 & Rat & 101 & ND & ND & ND & Urea, 3 & $*$ \\
\hline 3 & Rat & 117 & 30 & 19 & 30 & ND & 14 \\
\hline 4 & Rat & 55 & ND & ND & ND & Amino acids, 0 & 5 \\
\hline 4 & Rabbit & 96 & 21 & 26 & 24 & Amino acids, 14 & 3 \\
\hline 9 & Rabbit & 118 & 29 & 19 & 25 & ND & 25 \\
\hline \multicolumn{8}{|c|}{$\begin{array}{l}\text { Chronic hypernatremia } \\
d\end{array}$} \\
\hline 3 & Rat & 74 & ND & ND & ND & Polyols, 9 & 26 \\
\hline 4 & Rat & 83 & ND & ND & ND & Amino acids, 8 & 5 \\
\hline 4 & Mouse & 80 & 19 & 26 & ND & $\begin{array}{l}\text { Amino acids, } 28 \\
\text { Urea, } 9\end{array}$ & 6 \\
\hline 5 & Rat & 50 & ND & ND & ND & $\begin{array}{l}\text { Amino acids, } 14 \\
\text { Methylamines, } 4 \\
\text { Polyols, } 6\end{array}$ & 23 \\
\hline 7 & Rat & 80 & 25 & 1 & 25 & ND & 14 \\
\hline 7 & Rabbit & 80 & 8 & 5 & 15 & Amino acids, 42 & 3 \\
\hline & & 58 & 28 & 21 & 19 & ND & \\
\hline 7 & Rat & 102 & ND & ND & ND & $\begin{array}{l}\text { Amino acids, } 20 \\
\text { Methylamines, } 4 \\
\text { Polyols, } 3 \\
\text { Urea, } 8\end{array}$ & $*$ \\
\hline
\end{tabular}

ND, not determined. * Current study.

In summary, the brain content of myoinositol, betaine, GPC, and phosphocreatine are increased in rats with chronic hypernatremia and may account $7 \%$ of the observed increase in tissue osmolality. Sorbitol appears not to play a role in this experimental condition. Other organic solutes including glutamine, glutamate, taurine, and urea measured in this study can account for $28 \%$ of total osmolality change in chronic hypernatremia. During the recovery from hypernatremia, all these osmoles except myoinositol return to normal range in 2 d while myoinositol level remains elevated. The retention of myoinositol may have clinical implications concerning the development of brain edema accompanying rapid correction of hypernatremia.

\section{Acknowledgments}

We would like to thank Dr. Randolph Berens for his help with the HPLC assays and Dr. Maurice Burg for his helpful discussion of this project.

Dr. Y. H. Lien is supported by a National Kidney FoundationBurroughs Wellcome Corp. Fellowship Award. Dr. J. I. Shapiro is supported by an American Heart Association-Squibb Corp. Clinician Scientist Award.

\section{References}

1. Finberg, L. 1973: Hypernatremic dehydration in infants. $N$. Engl. J. Med. 289:196-200.
2. McDowell, M. E., A. V. Wolf, and A. Steer. 1955. Osmotic volume of distribution: idiogenic changes in osmotic pressure associated with administration of hypertonic solutions. Am. J. Physiol. 180:545-558.

3. Arieff, A. I., R. Guisado, and V. C. Lazarowitz. 1979. Pathology of hyperosmolar states. In Disturbances in Body Fluid Osmolarity. T. E. Andreoli, J. J. Grantham, and F. C. Rector, Jr., editors. American Physiological Society, Bethesda, MD. 227-250.

4. Pollock, A. S., and A. I. Arieff. 1980. Abnormalities of cell volume regulation and their functional consequences. Am. J. Physiol. 239:F195-F205.

5. Lockwood, A. H. 1975. Acute and chronic hyperosmolality. Arch. Neurol. 32:62-64.

6. Thurston, J. H., R. E. Hauhart, and J. A. Dirgo. 1980. Taurine: a role in osmotic regulation of mammalian brain and possible clinical significance. Life Sci. 26:1561-1568.

7. Yancey, P. H., M. E. Clark, S. C. Hand, R. D. Bowlus, and G. N. Somero. 1982. Living with water stress: evolution of osmolyte systems. Science (Wash. DC). 217:1214-1222.

8. Somero, G. N. 1986. Protons, osmolytes, and fitness of internal milieu for protein function. Am. J. Physiol. 251:R197-R213.

9. Balaban, R. S., and M. A. Knepper. 1983. Nitrogen-14 nuclear magnetic resonance spectroscopy of mammalian tissues. Am. J. Physiol. 245:C439-C444.

10. Wirthensohn, G., S. Lefrank, M. Schmolke, and W. G. Guder. 1989. Regulation of organic osmolyte concentrations in tubules from rat renal inner medulla. Am. J. Physiol. 256:F128-F135.

11. Bagnasco, S., R. Balaban, H. M. Fales, Y. M. Yang, and M. Burg. 1986. Predominant osmotically active organic solutes in rat and rabbit renal medullas. J. Biol. Chem. 261:5872-5877. 
12. Gullans, S. R., J. D. Blumenfeld, J. A. Balschi, M. Kaleta, R. M. Brenner, C. W. Heilig, and S. C. Hebert. 1988. Accumulation of major organic osmolytes in rat renal inner medulla in dehydration. Am. J. Physiol. 255:F626-F634.

13. Chan, P. H., and R. A. Fishman. 1979. Elevation of rat brain amino acids, ammonia and idiogenic osmoles induced by hyperosmolality. Brain Res. 161:293-301.

14. Holliday, M. A., M. N. Kalayci, and J. Harrah. 1968. Factors that limit brain volume changes in response to acute and sustained hyper- and hyponatremia. J. Clin. Invest. 47:1916-1928.

15. Weissbach, A. 1984. Myoinositol. In Methods of Enzymatic Analysis, Volume 6. H. U. Bergmeyer, editor. Verlag Chemie, Weinheim, FRG. 366-370.

16. Barak, A. S., and D. Tuma. 1981. Choline and betaine. Methods Enzymol. 72(Pt. D.):287-292.

17. Takayama, M., S. Itoh, T. Nagasaki, and I. Tanimizu. 1977. A new enzymatic method for determination of serum choline containing phospholipids. Clin. Chem. Acta 79:93-98.

18. Wolff, S. D., P. H. Yancey, T. S. Stanton, and R. S. Balaban. 1989. A simple HPLC method for quantitating major organic solutes of renal medulla. Am. J. Physiol. 256:F954-F956.

19. Wallerstein, S., C. I. Zucker, and J. L. Fleiss. 1980. Some statistical methods useful in circulation research. Circ. Res. 47:1-9.

20. Ullrich, K. J. 1956. Über das Vorkommen von Phosphorver- bindungen in verschiedenen Nierenabschnitten und Anderung ihrer Konzentration in Abhängigkeit vom Diuresezustand. Pflügers Arch. Gesamte Physiol. Menschen Tiere. 262:551-561.

21. Wirthensohn, G., F. X. Beck, and W. G. Guder. 1987. Role and regulation of glycerophosphorylcholine in rat renal papilla. Pflügers Arch. Eur. J. Physiol. 409:411-415.

22. Arieff, A. I., C. R. Kleeman, A. Keushkerian, and H. Bagdoyan. 1973. Studies on mechanisms of cerebral edema in diabetic comas: effects of hyperglycemia and rapid lowering of plasma glucose in normal rabbits. J. Clin. Invest. 52:571-583.

23. Heilig, C. W., M. E. Stromski, J. D. Blumenfeld, J. P. Lee, and S. R. Gullans. 1989. Characterization of the major brain osmolytes which accumulate in salt loaded rats. Am. J. Physiol. 257:F1108F1116.

24. Blaine, E. H., J. O. Davis, and R. T. Witty. 1970. Renin release after hemorrhage and after suprarenal aortic constriction in dogs without sodium delivery to the macula densa. Circ. Res. 27:1081-1089.

25. Sotos, J. F., P. R. Dodge, P. Meara, and N. B. Talbot. 1960. Studies in experimental hypertonicity. I. Pathogenesis of the clinical syndrome, biochemical abnormalities and cause of death. Pediatrics. 26:925-938.

26. Lohr, J. W., J. McReynolds, T. Grimaldi, and M. Acara. 1988. Effect of acute and chronic hypernatremia on myoinositol and sorbitol concentration in rat brain and kidney. Life Sci. 43:271-276. 